\title{
ANÁlise da QUALIDAde da ÁGUA DE TRÊS PROPRIEDADES RURAIS DO MUNICÍPIO DE FLORIANO, PIAUÍ
}

Cynthia Raquel do Nascimento Araújo de Sousa ${ }^{1}$, Amando Oliveira Matias ${ }^{1}$, Florisvaldo Clementino Santos Filho ${ }^{1}$, Ricardo Gondim Sarmento ${ }^{1}$, Maria Fernanda Costa Gomes ${ }^{2}$, Marcones Ferreira Costa ${ }^{1 *}$

\begin{abstract}
RESUMO - As comunidades rurais são negligenciadas quando se trata de saneamento básico e garantia de qualidade hídrica, tendo em vista a falta de tratamento e saneamento básico na zona rural. O presente trabalho teve como escopo principal analisar a potabilidade da água de três comunidades rurais da cidade de Floriano-PI, por meio de parâmetros físico-químicos e microbiológicos, no período de agosto de 2018 . Foram avaliados os seguintes parâmetros físico-químicos: $\mathrm{pH}$, turbidez, alcalinidade, cloreto, nitrato e nitrito. Além disso, foi analisada a presença de coliformes totais. As análises foram realizadas no laboratório físico-químico e bacteriológico da Companhia de Águas e Esgotos do Piauí (Agespisa). Com base na análise dos resultados pode-se observar que as amostras avaliadas indicaram a potabilidade da água, visto que as mesmas encontram-se dentro dos valores máximos estabelecidos pela Portaria nº. 2.914/2011 do Ministério da Saúde.
\end{abstract}

Palavras chave: físico-química, microbiológica, potabilidade.

\section{ANALYSIS OF WATER QUALITY OF THREE RURAL PROPERTIES IN THE MUNICIPALITY OF FLORIANO, PIAUÍ}

\begin{abstract}
Rural communities are neglected when it comes to basic sanitation and water quality assurance, given the lack of basic sanitation and treatment in the rural area. The main objective of this study was to analyze the water potability of three rural communities in the city of Floriano-PI, using physicochemical and microbiological parameters in the period of August 2018. The following physical and chemical parameters were evaluated: $p H$, turbidity, alkalinity, chloride, nitrate and nitrite. In addition, the presence of total coliforms was analyzed. The analyzes were carried out in the physical-chemical and bacteriological laboratory of Companhia de Águas e Esgotos do Piauí (Agespisa). Based on the analysis of the results it can be observed that the samples evaluated indicated the potability of the water, since they are within the maximum values established by Ordinance no. 2,914 / 2011 of the Ministry of Health.
\end{abstract}

Keywords: microbiological, physico-chemical, potability.

\section{INTRODUÇÃO}

As comunidades rurais necessitam de água para manter suas atividades, a potabilidade desse recurso pode ser modificada por vários fatores. Os principais agentes poluidores da água são: matéria orgânica biodegradável, sólidos em suspensão, nutrientes, patógenos, matéria orgânica não biodegradável e metais pesados (Metcalf \& Eddy, 2015). Nessa perspectiva, as principais fontes de contaminação hídrica, em muitos casos, estão diretamente associadas às atividades antropogênicas (Flores et al., 2017)

A utilização de água potável é um dos fatores que garantem a qualidade de vida. De modo geral, entendese que a contaminação do solo e os hábitos de higiene afetam a potabilidade desse recurso. Souza et. al (2011) relatam que no Nordeste Brasileiro a contaminação

\footnotetext{
${ }^{1}$ Universidade Federal do Piauí, Campus Amílcar Ferreira Sobral, BR 343, km 3,5 - Bairro Meladão, Floriano, PI, Brasil, 64808-605.*Autor para correspondência: marconescosta@ufpi.edu.br

${ }^{2}$ Universidade Estadual do Piauí, Campus Prof. Ariston Dia Lima, R. Antônio Carvalho, São Raimundo Nonato - PI, Brasil, 64770-000
} 
de olhos d'água e açudes ocorre pela falta de hábitos higiênicos da população, o que representa um grande problema, principalmente na zona rural, visto que a ingestão de água contaminada é responsável pela ocorrência de doenças como: diarreias, disenterias, hepatites e cólera (Yamaguchi et al., 2013).

Uma questão que afeta a qualidade da água no meio rural é a falta de fiscalização e a insciência da população para elevada ocorrência de doenças vinculadas à contaminação hídrica nas comunidades rurais (Cavalcante, 2014). Segundo Birkheuer (2017), no meio rural a água é vulnerável a várias modificações, visto que o abastecimento hídrico dessas regiões consiste, principalmente, em nascentes e poços artesianos que, normalmente, não possuem o devido cuidado sanitário, já que, em alguns casos, essas áreas encontram-se próximos a pastagem animal, esterqueiras ou abatedouros, locais que favorecem a contaminação por microrganismos. Diante disto, são necessárias medidas de controle de qualidade, por meio de regulamentos técnicos específicos e legislações que garantam o consumo de água potável nas comunidades rurais (Morais et al., 2016).

Conforme Bortoli (2016), este monitoramento é realizado por intermédio de análises laboratoriais e os principais parâmetros de qualidade de água consistem em avaliações físico-químicos (cor, turbidez, condutividade elétrica, temperatura, $\mathrm{pH}$, alcalinidade, dureza total, ferro, cloretos, oxigênio dissolvido, oxigênio consumido, cloro residual livre, sólidos totais, amônia) e microbiológicos (coliformes totais e termotolerantes e bactérias mesófilas aeróbias), conforme às Resoluções do Conselho Nacional do Meio Ambiente (CONAMA) $\mathrm{n}^{\circ}$ 430/2011 (BRASIL, 2011) e n ${ }^{\circ} 396 / 2008$ (BRASIL, 2008) e a Portaria do Ministério da Saúde no ${ }^{\circ}$ 2914/2011 (BRASIL, 2011).

Pensando na saúde da população rural e como esta pode ser prejudicada devido ao consumo de água contaminada, esta pesquisa tem por finalidade avaliar a potabilidade desse recurso em três comunidades rurais da cidade de Floriano no Piauí: Barra do Coqueiro, Barra da Itaueira e no Assentamento Bom Jardim. Deste modo, procuramos responder a seguinte questão: A água utilizada para o consumo humano e animal nas três áreas rurais do município de Floriano-PI encontramse dentro dos padrões de potabilidade exigidos pela legislação vigente? Para responder esta pergunta, o presente trabalho analisou os parâmetros físico-químicos e microbiológicos de modo a fornecer informações relacionadas à qualidade da água utilizada para o consumo nessas áreas rurais.

\section{MATERIAL E MÉTODOS}

Foram selecionadas três comunidades rurais do município de Floriano: Barra do Coqueiro, Barra da Itaueira e o Assentamento Bom Jardim. A coleta das amostras de água foi realizada no mês de agosto de 2018, período de seca da região. Os materiais necessários para essa etapa foram: caixa de isopor limpa e esterilizada; gelo em gel; 3 frascos coletores concedidos pela Companhia de Águas e Esgotos do Piauí (Agespisa); luvas, sabão neutro, álcool 70\%, algodão, fita adesiva, ficha para anotação dos dados, folha A4 e caneta.

A coleta das amostras para o exame bacteriológico ocorreu da seguinte forma: após a limpeza das mãos e utilizando as luvas para desinfetar as torneiras com detergente neutro e álcool $70 \%$, a amostra foi colhida em um frasco de coleta e vedado com cuidado para não haver vazamento. Para o exame físico-químico, as amostras foram coletadas em frascos esterilizados e mantidas em caixas de isopor com gelo até a chegada ao laboratório para análise. Foi realizado o preenchimento da ficha de roteiro, onde constam o nome da comunidade, município da coleta, data, horário e número das amostras. Esses procedimentos foram executados nas três localidades estudadas.

Posteriormente, foram determinados os seguintes parâmetros físico-químicos: turbidez, $\mathrm{pH}$, alcalinidade, cloretos, nitrato e nitrito. As análises foram determinadas no Laboratório Físico-Químico da Agespisa, em FlorianoPI. Os parâmetros químicos, alcalinidade e cloretos foram determinados por meio de análises titulométricas seguindo os procedimentos do Manual Prático de Análise de Água (FUNASA, 2014).

O parâmetro da turbidez foi determinado pelo método nefelométrico (modelo portátil 2100 P Turbidimer), onde se transferiu $15 \mathrm{~mL}$ de cada amostra para a cubeta de vidro contida no turbidímetro para realização da leitura e obtenção dos resultados.

Para análise do $\mathrm{pH}$, foram realizados testes colorimétricos comparativos com indicador reagente azul de bromotimol. Na análise da alcalinidade, empregouse o método analítico de titulação de neutralização, usando como titulante uma solução de ácido sulfúrico 
$\left(\mathrm{H}_{2} \mathrm{SO}_{4}\right)$ 0,02N na presença dos indicadores: fenolftaleína e solução indicadora verde de bromocresol/vermelho de metila.

$\mathrm{Na}$ avaliação de nitrato e nitrito, foi realizado o teste de colorimetria com reagente NitriVer ${ }^{\circledR} 3 \mathrm{Nitrite}$ Reagent com auxílio do espectrofotômetro HACH-DR 5000. O método de avaliação de cloretos ocorreu a partir de titulação argentométrica (Método de Mohr), usando como uma titulante solução padrão de nitrato de prata $\left(\mathrm{AgNO}_{3}\right) 0,0141 \mathrm{~N}$ na presença do indicador cromato de potássio $\left(\mathrm{K}_{2} \mathrm{CrO}_{4}\right)$.

Para quantificação dos indicadores microbiológicos, foi realizada uma limpeza da bancada do laboratório com álcool 92,8 \% e, em seguida, flambada para evitar ao máximo a contaminação da amostra por microrganismos externos. Logo após, foi adicionado COLILERT $^{\circledR}$ nas amostras de água. Essa metodologia foi aprovada pela United States Environmetal Protection Agency (USEPA) (Marquezi et al., 2010), que utiliza nutrientes (açúcares ligados a radicais orgânicos cromogênicos) que fazem com que os microrganismos de interesse presentes na amostra produzam uma mudança de cor (ou fluorescência) no sistema inoculado. Em seguida as amostras foram armazenadas em estufa a $36^{\circ}-37^{\circ}$ durante 24 horas, para posterior análise dos resultados.

Para a interpretação dos resultados, foram considerados os limites expostos da seguinte norma: Portaria 2.914/11 do Ministério da Saúde (M.S.) que define a potabilidade da água (BRASIL, 2011) e na Resolução CONAMA n 396, de 03 de abril de 2008.

\section{RESULTADOS E DISCUSSÃO}

As definições dos parâmetros analisados nesta pesquisa estão apresentadas na Tabela 1 .

Os resultados obtidos pelo exame bacteriológico indicam a ausência de contaminação por coliformes totais e E.coli pela metodologia COLILERT ${ }^{\circledR}$, uma vez que o meio permaneceu incolor, indicando ausência de bactérias do grupo coliforme e E. coli nas amostras (Tabela 2).

Conforme a tabela 2 e seguindo a referência da Portaria $\mathrm{n}^{\circ} 2.914$, de dezembro de 2011 do Ministério da Saúde, pode-se afirmar que a água das três comunidades contempla o item 03 desta portaria, atendendo assim aos padrões microbiológicos de potabilidade. Resultados semelhantes foram obtidos por Morais et al. (2016) ao avaliarem a qualidade da água distribuída aos habitantes de três bairros da cidade de Rio Verde, em Goiás, na qual todas as amostras atenderam aos limites determinados pela referida Portaria com relação ao exame microbiológico.

A água utilizada para abastecimento deve apresentar características sanitárias e toxicológicas adequadas, estando livres de organismos patogênicos e sustâncias nocivas à saúde. O recurso do planejamento hídrico deve, não só dar direito à água, mas garantir que esta seja de qualidade promovendo o bem-estar físico e econômico (Scalize et al., 2016).

O pH é um importante parâmetro, por indicar a acidez ou alcalinidade das soluções. A partir desta análise, pode-se conhecer a qualidade de dejetos industriais lançados na água, uma vez que o $\mathrm{pH}$ influencia a precipitação de elementos químicos tóxicos como metais pesados (Santos \& Mohr, 2013). O pH das águas dos três poços apresentou valores de 7,5; 7,3 e 7,2 (Tabela 3), enquadrando-se dentro do limite recomendado pela Portaria ${ }^{\circ}$ 2.914/11 do Ministério da Saúde para águas destinadas ao consumo humano (BRASIL, 2011). Quando o $\mathrm{pH}$ apresentar valores superior a 7,0 favorece o aumento da alcalinidade, comprometendo a palatabilidade e o consumo da água (Crispim et al., 2017).

A turbidez está relacionada à presença de partículas suspensas na água e modificações neste parâmetro são identificadas em períodos de chuvas intensas, que também podem alterar os valores do $\mathrm{pH}$ e da alcalinidade (Almeida et al., 2017). Os valores de turbidez das amostras de água dos três poços foram de 1,9; 4,3 e 2,0 (Tabela 4) enquadraram-se dentro do valor máximo de 5,0 uT (unidade Jackson ou nefelométrica de turbidez) estabelecido pela Portaria 2.914/11 do Ministério da Saúde.

A alcalinidade mede a capacidade da água em neutralizar ácidos, resultante da presença de carbonatos, bicarbonatos e hidróxidos (Bezerra et al., 2018). A Organização Mundial de Saúde (OMS) (1999) estima que o valor máximo permitido da alcalinidade total em águas para consumo humano é de $400 \mathrm{mg} / \mathrm{L}$. Com base nesta referência, verificou-se que as águas analisadas apresentaram valores no intervalo estabelecidos pela OMS variando entre 115 a $210 \mathrm{mg}$ L (Tabela 5). Em águas para o consumo humano, a 
Tabela 1 - Conceitos dos parâmetros analisados, com base em Bortoli (2016)

\section{Parâmetros}

Turbidez

Alcalinidade

Cloretos

Nitrato, nitrito

Bacteriológico/microbiológico

$\mathrm{pH}$
Conceito

A turbidez é um parâmetro que identifica a presença de partículas em suspensão na água, é gerada pela matéria em suspensão, que dispersa e absorve a luz impedindo a passagem da mesma. Fontes de matéria orgânica e concentrações elevadas de microrganismos formam a matéria em suspensão nas águas naturais, deixando-as turva.

A alcalinidade é medida por meio da quantificação de sais alcalinos, principalmente de sódio e cálcio; mede a capacidade da água de neutralizar os ácidos, isto é a quantidade de substâncias que atuam como um tampão, em teores elevados, pode proporcionar sabor desagradável à água, tem influência nos processos de tratamento da água.

Os cloretos estão presentes em quase todas as águas naturais, são advindos da dissolução de sais, como por exemplo, o cloreto de sódio, assim o teor de cloretos das águas tem por finalidade obter informações sobre o seu grau de mineralização ou indícios de poluição. A presença desse elemento acelera os processos de corrosão em tubulações de aço e alumínio, além de alterar o sabor da água. Concentrações elevadas de cloretos em águas doces são indicadores de poluição por esgoto doméstico.

Em corpos d'água o nitrogênio pode ser encontrado nas formas de: nitrogênio orgânico, nitrogênio amoniacal, nitrito e nitrato. As fontes de nitrogênio para os corpos d'água são variadas, sendo uma das principais o lançamento de esgotos sanitários e efluentes industriais.

Dada suas características biológicas, as águas naturais são constituídas de diversos microrganismos capazes de transmitir doenças e agir na transformação da matéria orgânica (ciclos biogeoquímicos o nitrogênio, por exemplo). O grupo dos coliformes é constituído por bactérias encontradas no trato intestinal dos animais de sangue quente. Os coliformes são classificados como: coliformes totais e termotolerantes. As bactérias coliformes englobam diversos grupos, constituídos por diferentes gêneros (Klebsiella, Escherichia, Serratia, Erwenia e Enterobacter), surgem dos esgotos e da massa fecal encontrada em animais de sangue quente. Para que a água esteja contaminada por coliformes termotolerantes é necessário haver matéria fecal no local ou nas proximidades.

Esse parâmetro representa a concentração de íons hidrogênio $\mathrm{H}^{+}$, dando uma indicação sobre a condição de acidez, neutralidade ou alcalinidade da água. Um pH baixo representa potencial corrosividade e agressividade às tubulações ou peças de abastecimento de água. Quando o pH estiver alto, há possibilidade de incrustações nas peças de abastecimento. É importante avaliar o potencial.

Fonte: Bortoli, 2016.

Tabela 2 - Resultados do exame bacteriológico da água dos poços das comunidades rurais

\begin{tabular}{|c|c|c|c|}
\hline \multicolumn{4}{|c|}{ Exame bacteriológico } \\
\hline Comunidade rural & $\begin{array}{l}\text { Contagem padrão } \\
\text { de colônias de bactérias }\end{array}$ & $\begin{array}{l}\text { Coliformes totais } \\
\text { (N.M.P./100mL) }\end{array}$ & $\begin{array}{l}\text { Escherichia coli } \\
\text { (N.M.P./100mL) }\end{array}$ \\
\hline Barra do Coqueiro & - & Ausência & Ausência \\
\hline Barra da Itaueira & - & Ausência & Ausência \\
\hline Assentamento Bom Jardim & - & Ausência & Ausência \\
\hline
\end{tabular}

Fonte: Sousa, 2018. 
alcalinidade em concentrações moderadas não possui significado sanitário. Entretanto, em níveis elevados, pode ocasionar um sabor desagradável (Assis et al., 2017).

Concentrações altas de cloretos podem restringir o uso da água, em razão do sabor salgado que eles conferem e pelo efeito laxativo que eles podem provocar (BRASIL, 2014). A Portaria $\mathrm{n}^{\circ}$ 2.914/2011 do Ministério da Saúde estabelece o teor de $250 \mathrm{mg} / \mathrm{L}$ como o valor máximo permitido para água potável. Os resultados obtidos (Tabela 6) apresentam valores para a concentração de cloretos dentro da faixa estabelecida pelo Ministério da Saúde.

As análises de nitrito e nitrato são importantes, visto que esses compostos são encontrados em águas subterrâneas devido sua alta mobilidade, sendo indicadores de contaminação mundialmente utilizados. O consumo desses compostos por meio das águas de abastecimento está associado a efeitos adversos à saúde, como a indução à metemoglobinemia, especialmente em crianças, e a formação potencial de nitrosaminas e nitrosamidas carcinogênicas (Silva \& Brotto, 2014)

O padrão de potabilidade para o nitrito é de no máximo $1,0 \mathrm{mg} / \mathrm{L}$ e para o íon nitrato o padrão máximo permitido é de $10 \mathrm{mg} / \mathrm{L}$. Os teores encontrados nas amostras avaliadas nos três poços indicam que a concentração desses compostos está conforme os valores preconizados na legislação para o consumo humano, visto que nenhuma concentração de nitrito e nitrato foi observada nos 3 poços.

Tabela 3 - pH da água dos poços das comunidades rurais

\begin{tabular}{lccc}
\hline Comunidade rural & $\mathrm{pH}$ & V.M.P. & Resultado \\
\hline Barra do Coqueiro & - & 6,0 a 9,5 & 7,5 \\
Barra da Itaueira & - & 6,0 a 9,5 & 7,3 \\
Assentamento Bom Jardim & - & 6,0 a 9,5 & 7,2 \\
\hline
\end{tabular}

Fonte: Sousa, 2018.

Tabela 4 - Turbidez da água dos poços das comunidades rurais

\begin{tabular}{lccc}
\hline Comunidade rural & Turbidez & V.M.P. & Resultado \\
\hline Barra do Coqueiro & UT & 5,0 & 1,9 \\
Barra da Itaueira & UT & 5,0 & 4,3 \\
Assentamento Bom Jardim & UT & 5,0 & 2,0 \\
\hline
\end{tabular}

Fonte: Sousa, 2018.

Tabela 5 - Alcalinidade bicarbonato da água dos poços das comunidades rurais

\begin{tabular}{lcc}
\hline Comunidade rural & Alc. bicarbonato V.M.P.(mg/L) & Resultados \\
\hline Barra do Coqueiro & 400 & 210,0 \\
Barra da Itaueira & 400 & 229,0 \\
Assentamento Bom Jardim & 400 & 115,0 \\
\hline
\end{tabular}

Fonte: Sousa, 2018.

Tabela 6 - Cloretos da água dos poços das comunidades rurais

\begin{tabular}{lcc}
\hline CComunidade rural & Cloretos V.M.P.(mg/L) & Resultados \\
\hline Barra do Coqueiro & 250 & 200 \\
Barra da Itaueira & 250 & 150 \\
Assentamento Bom Jardim & 250 & 220 \\
\hline
\end{tabular}

Fonte: Sousa, 2018. 


\section{CONCLUSÃO}

Com base nos resultados dos parâmetros físicoquímicos e microbiológicos, pode-se perceber que a água destinada ao abastecimento e consumo das três comunidades rurais em Floriano-PI apresentam valores conforme os padrões de potabilidade para o consumo humano recomendados pela Portaria $\mathrm{n}^{\circ} 2.914 / 11$ do Ministério da Saúde e da Resolução CONAMA n 396/ 08 . Entretanto é necessário um monitoramento constante desse recurso hídrico, visto que o atendimento aos parâmetros que asseguram a potabilidade da água não pode ser realizado apenas em um dado momento, mas deve ocorrer de forma contínua, a fim de evitar o desenvolvimento de doenças relacionadas ao consumo de água contaminada.

\section{AGRADECIMENTOS}

Os autores agradecem aos responsáveis pelos poços escolhidos como pontos de coleta, pelo auxílio no repasse das informações necessárias a este estudo e à Companhia de Águas e Esgotos do Piauí (Agespisa), por conceder a infraestrutura necessária para a realização das análises físico-químicas e microbiológica.

\section{LITERATURA CITADA}

ALMEIDA, M. C.; SILVA, M. M.; PAULA, M. Avaliação do desempenho de uma estação de tratamento de água em relação à turbidez, cor e $\mathrm{pH}$ da Água. Revista Eletrônica de Gestão e Tecnologias Ambientais, v. 5, n. 1, p. 25-40, 2017.

ASSIS, D. M. S. et al. Avaliação dos parâmetros físico-químicos da água de abastecimento em diferentes bairros do Município de Salvaterra (Arquipélago do Marajó, PA). Revista Virtual de Química, v. 9, n. 5, 2017.

BEZERRA, A. D. A. et al. Análise situacional da qualidade de água subterrânea oriunda de poços da região metropolitana de Fortaleza, Ceará, brasil. Acta Biomedica Brasiliensia, v. 9, n. 1, p. 94-104, 2018.

BRASIL. Conselho Nacional do Meio Ambiente. Resolução CONAMA $n^{\circ} 396.03$ de abril de 2008.
BRASIL. Ministério da Saúde. Portaria nº 2.914 de 12 de dezembro de 2011. Dispõe sobre os procedimentos de controle e de vigilância da qualidade da água para consumo humano e seu padrão de potabilidade. Diário Oficial da República Federativa do Brasil, Brasília, 2011, Seção 1, do dia 26 seguinte, página 266.

BRASIL. Ministério da Saúde. Fundação Nacional de Saúde. Manual de controle da qualidade da água para técnicos que trabalham em ETAS. Ministério da Saúde, Fundação Nacional de Saúde. Brasília: Funasa, 2014.112p.

BORTOLI, J. Qualidade físico-química e microbiológica da água utilizada para consumo humano e dessedentação animal em propriedades rurais produtoras de leite na região do Vale do Taquari/RS. 2016. Dissertação de Mestrado.

BIRKHEUR, C. F. et al. Qualidade físico-química e microbiológica da água de consumo e animal do Brasil: análise sistemática. Revista Caderno Pedagógico, v.14, n.1, 2017.

CAVALCANTE, R. B. L. Ocorrência de Escherichia coli em fontes de água e pontos de consumo em uma comunidade rural. Ambiente \& Água Interdisciplinary Journal of Applied Science, v. 9, n. 3, 2014.

CRISPIM, D. L. et al. Análise físico-química das águas de três poços Amazonas no centro da cidade de Pombal-PB. Geografia Ensino \& Pesquisa, v. 21, n. 2, p. 155-163, 2017.

FLORES, É. L. M.; CAMPOS, R. F.; WITCEL, C. et al. Determinação de ânions para análise da qualidade da água subterrânea no município de Medianeira (PR). Águas Subterrâneas, v.31, n.4, 292-298, 2017.

MARQUEZI, M. C. Comparação de metodologias para a estimativa do número mais provável (NMP) de coliformes em amostras de água. 2010. Tese de Doutorado. Universidade de São Paulo.

METCALF, L.; EDDY, H.P. Tratamento de efluentes e recuperação de recursos. McGraw Hill Brasil, 2015. 
MORAIS, W. A. et al. Qualidade sanitária da água distribuída para abastecimento público em Rio Verde, Goiás, Brasil. Caderno de Saúde Coletiva, v. 3, n. 24, p. 361-367, 2016.

SANTOS, R. S.; MOHR, T. Saúde e qualidade da água: análises microbiológicas e físico-químicas em águas subterrâneas. Revista contexto \& Saúde, IJUí, v. 13, n. 24-25, p. 46-53, 2013.

SCALIZE, P. S. et al. Avaliação da qualidade da água para abastecimento no assentamento de reforma agrária Canudos, Estado de Goiás. Revista Ambiente \& Água, v.9, n.4, 2014.
SILVA, L. C. M.; BROTTO, M. E. Nitrato em água: ocorrência e consequências. Escola Superior de Química, São Paulo, 2014.

SOUZA, S.H.B et al. Avaliação da qualidade da água e da eficácia de barreiras sanitárias em sistemas para aproveitamento de águas de chuva. Revista Brasileira de Recursos Hídricos, v. 16, n. 3, p. 81-93, 2011.

YAMAGUCHI, M. U. et al. Qualidade microbiológica da água para consumo humano em instituição de ensino de Maringá-PR. O Mundo da Saúde, v. 37, n. 3, p. 312-320, 2013.

Recebido para publicação em 14/2/2019 e aprovado em 24/6/2019. 